\title{
Developing a Typology of Organisational Forms of Cooperative Purchasing
}

\author{
Schotanus, Fredo; Telgen, Jan \\ Journal of Purchasing \& Supply Management 13 (2007) 53-68
}

\begin{abstract}
This paper develops a typology for purchasing groups. In the typology, five ideal forms of cooperative purchasing are distinguished based on seven main dimensions. The forms are positioned in a matrix according to two distinguishing dimensions. These two dimensions are the 'influence by all members on the group activities' and the 'number of different group activities'. Underlying the two-dimensional matrix, there are five other dimensions that do not distinguish all forms from each other, but further detail the forms of cooperative purchasing. The typology can serve as a guideline for purchasing groups when a suitable organisational form needs to be chosen. In a suitable form, the dimensions of a group fit the circumstances. For all groups, it is recommended to find this best fit. This is something in which the typology may help. The paper concludes by emphasising the importance of clearly defining and positioning studied forms, because different forms imply different research models and have different advantages, disadvantages, and critical success factors.
\end{abstract}

Keywords: Typology; Purchasing group; Organisational forms

\section{Introduction}

Cooperative purchasing has so far been loosely defined in the existing literature. It is referred to as horizontal cooperative purchasing, group purchasing, collaborative purchasing, collective purchasing, joint purchasing, consortium purchasing, shared purchasing, bundled purchasing, et cetera. And this list goes on to about a hundred terms. Thus, despite the fact that cooperative purchasing is as old as ancient Egypt and Babylon (Wooten, 2003), the terminology is broad and not yet fully stabilised (Kivisto et al., 2003). In the literature, group purchasing and cooperative purchasing are among the most popular terms. In this paper, the terms 'cooperative purchasing' and 'purchasing group' are used. Cooperative purchasing is defined as the cooperation between two or more organisations in a purchasing group in one or more steps of the purchasing process by sharing and/or bundling their purchasing volumes, information, and/or resources. A purchasing group is defined as an organisation in which cooperative purchasing processes take place. A purchasing group consists of dependent or independent organisations that share and/or bundle together in order to achieve mutually compatible goals that they could not achieve easily alone (based on Hendrick 1997; Lambe et al. 2002).

Typical advantages of cooperative purchasing are lower purchasing prices, higher quality, lower transaction costs, reduced workloads, reduced (supply) risks, and learning from each other. Typical disadvantages are set-up costs, coordination costs, loosing flexibility, loosing control, supplier resistance, and possible interference by anti-trust legislation (Schotanus, 2005a). The advantages of cooperative purchasing outweigh the 
disadvantages for many situations in the public and private sector as is discussed later on in this paper.

The concept of cooperative purchasing seems to be especially interesting for public organisations, for instance, for organisations like public hospitals, schools, ministries or municipalities. Cooperative purchasing seems interesting for these types of organisations as there is no or almost no mutual competition. In addition, there is often a common external environment, mutual trust, mutual interests, and one common goal: to maximise the value of the taxpayers' money. Finally, similar types of public organisations often have similar organisational structures, similar networks, and similar purchasing needs. All these factors are usually considered as stimuli to cooperation. For further discussions of cooperation stimuli, see among others Ariño and Torre (1998), Barkema et al. (1997), Chung et al. (2000), Cruijssen et al. (2006), Doucette (1997), Galaskiewicz (1985), Ireland et al. (2002), and Nollet and Beaulieu (2005). Since most purchasing groups in the public sector are modelled on a non-profit basis, savings are generated with little cost for the group members and as a result, the majority of the savings flows directly to the members (Kenney, 2000). Summarising, cooperative purchasing is considered as an interesting concept for private organisations, but is especially interesting for public organisations.

This paper focuses on developing a typology of different forms of cooperative purchasing. Developing such a typology is important for two reasons. First, it can be used to clearly define and position the studied organisational form of a purchasing group as it is not possible to put all different forms of cooperative purchasing in one box. Second, a typology can be used to design a purchasing group in which the different dimensions of the group fit together and fit the external circumstances. Here, the grand theoretical assertion is that an optimal fit should lead to organisational effectiveness of the purchasing group. If the dimensions of the group are not coherent, then this may lead to failure or a relatively low performance of the group.

The three main objectives of this paper link to the aspects mentioned above. The objectives are (1) to describe the main ideal forms of cooperative purchasing, (2) to develop a typology of the main ideal forms of cooperative purchasing, and (3) to position the main ideal forms of cooperative purchasing. This paper does not focus on general cooperation aspects that apply to all forms of cooperative purchasing. Examples of such aspects are typical advantages of cooperative purchasing, such as lower purchasing prices, reduced transaction costs, et cetera. In addition, this paper only focuses on the main forms of cooperative purchasing. For this reason, this paper does not expand much on hybrid forms. Finally, this paper does not focus on aspects and success factors that typically apply to about the same extent to all forms of cooperating. An example of such aspects and success factors is voluntary or involuntary cooperation. It is assumed that well-organised purchasing groups perform best when they are voluntary. A well-organised purchasing group should be cost-effective for all its members. In an ideal situation, this cost-effectiveness should attract members without enforcing them to cooperate.

The organisation of the rest of this paper is as follows. Section 2 provides a literature review and discusses the research relevance. The methodology is described in Section 3. Section 4 aims to achieve the first objective. Here, the main ideal forms of cooperative purchasing are described. Section 5 aims to achieve the second objective by developing a typology of different forms of cooperative purchasing. Section 6 aims to achieve the final objective. In this section, the main ideal forms of cooperative 
purchasing are positioned. In the final section, conclusions are drawn and recommendations are provided for practitioners and scholars in the field.

\section{Literature review}

Despite its long history, cooperative purchasing has received relatively little attention in social sciences (Essig, 2000; Laing and Cotton, 1997; Tella and Virolainen, 2005). Especially compared to vertical buyer-seller cooperation, horizontal buyer-buyer cooperation has not been a major research area until now (Ellram, 1991; Essig, 2000;

Patterson et al., 1999). The lack of research attention seems unjustified with cooperative purchasing being more well-established in practice (Doucette, 1997; Nollet and Beaulieu, 2003; Schotanus et al., 2004).

The increased attention in practice is confirmed by numerous publications on cooperative purchasing in refereed or peer-reviewed professional journals. Especially professional health sector journals pay attention to cooperative purchasing. This particular interest is explained by a long tradition of cooperative purchasing in this sector in the United States. Academic articles - published in international journals recognised within its sector - dealing explicitly with cooperative purchasing are still quite rare though. This is illustrated in Appendix 1, in which the main academic contributions to the field of cooperative purchasing are provided. Books are not included in this appendix since the content of relevant books mostly overlaps with the academic publications.

Appendix 1, with eight recent publications on a total of eighteen, shows that the academic attention for cooperative purchasing is increasing. This attention seems to have been growing mainly due to the development of electronic purchasing and an increased awareness and importance of the purchasing function. The existing research has contributed to describing and analysing several important cooperative purchasing topics under different settings and circumstances. The existing research findings are categorised as follows:

- Disadvantages and advantages of cooperative purchasing (Ball and Pye, 2000; Evans, 1987; Hone, 1974; Johnson, 1999; Nollet and Beaulieu, 2005; Stinchcombe, 1984; Tella and Virolainen, 2005);

- Critical success factors, drivers, and preconditions for cooperative purchasing (Doucette, 1997; Exworthy and Peckham, 1998; Essig, 2000; Huber et al., 2004; Laing and Cotton, 1997);

- Coordination structure of purchasing groups (Enthoven, 1994; Galaskiewicz, 1985);

- Formation of purchasing groups in electronic marketplaces (Granot and Sošic, 2005; Yuan and Lin, 2003);

- Development of purchasing groups over time (Ball and Pye, 2000; D'Aunno and Zuckerman, 1987; Johnson, 1999; Nollet and Beaulieu; 2003).

It is concluded that several relevant topics have been studied. Still, some gaps exist in the cooperative purchasing literature. Gaps are found in the research method used, as few large scale empirical research exists. Gaps are also be found in several research areas, as no academic publications were found related to the topics described in Table 1. Note that some of the topics mentioned in Table 1 have been discussed in professional journals, conference proceedings or in dissertation proposals. 
Table 1

Possible gaps in the academic literature on cooperative purchasing

\begin{tabular}{|c|c|}
\hline $\begin{array}{l}\text { Journal areas }{ }^{\mathrm{a}} \text { (number of current } \\
\text { publications) }\end{array}$ & $\begin{array}{l}\text { Possible gaps in the academic literature on cooperative } \\
\text { purchasing }\end{array}$ \\
\hline Communication (1) & $\begin{array}{l}\text { How to develop an effective and efficient communication } \\
\text { structure for a purchasing group? }\end{array}$ \\
\hline Economics (1) & $\begin{array}{l}\text { How can cooperative purchasing benefit organisations in } \\
\text { developing countries? }\end{array}$ \\
\hline Entrepreneurship (0) & $\begin{array}{l}\text { How can cooperative purchasing benefit small and medium-sized } \\
\text { enterprises (SMEs)? }\end{array}$ \\
\hline Finance and accounting (0) & $\begin{array}{l}\text { How to allocate the costs and gains of a purchasing group } \\
\text { between the members of the group? }\end{array}$ \\
\hline General and strategy journals (2) & How to develop a (purchasing) strategy for a purchasing group? \\
\hline Human resource management (0) & What is the impact of cooperative purchasing on employment? \\
\hline Industrial relations $(0)$ & $\begin{array}{l}\text { What is the impact of cooperative purchasing on buyer-supplier } \\
\text { and buyer-buyer relations? }\end{array}$ \\
\hline $\begin{array}{l}\text { Information systems and knowledge } \\
\text { management journals (2) }\end{array}$ & $\begin{array}{l}\text { What is the effect of information and experience sharing in a } \\
\text { purchasing group on the performance of the group members? }\end{array}$ \\
\hline Innovation (0) & $\begin{array}{l}\text { How to stimulate innovation in cooperative purchasing despite } \\
\text { decision making towards compromises? }\end{array}$ \\
\hline $\begin{array}{l}\text { Management science, production, } \\
\text { and operations journals ( } 3 \text { ) }\end{array}$ & What is the optimal size of a purchasing group? \\
\hline Marketing (0) & How to increase the sales of an electronic purchasing group? \\
\hline Organisational behaviour (0) & How to measure the performance of a purchasing group? \\
\hline Public sector (3) & $\begin{array}{l}\text { What are the intensity, efficiency, and effectiveness of } \\
\text { purchasing groups in the public sector? }\end{array}$ \\
\hline Purchasing and supply (4) & $\begin{array}{l}\text { What is the relationship between the organisational structure of a } \\
\text { purchasing group and its performance? }\end{array}$ \\
\hline
\end{tabular}

Sociology (2) How can cooperative purchasing benefit sustainable purchasing?

a The topics are based on the journal list of Harzing (2005), purchasing and supply has been added to this list

Table 1 shows that there are many research opportunities in cooperative purchasing. This paper focuses on research opportunities that link to existing research and several research questions from Table 1. The next subsections works up to these opportunities.

The existing research findings in Appendix 1 and the answers to the research questions in Table 1 depend on the settings and circumstances of purchasing groups. For instance, based on Mintzberg's $(1979,1983)$ theory of organisational structure, it is expected that the answer to the first communication question in Table 1 depends on the organisational form of a purchasing group. It is expected that a very large third party purchasing group should have a different communication structure than a very small intensive purchasing group. A similar argumentation can be applied to the answers to the other questions in Table 1 and to the existing research findings in Appendix 1. It is concluded that many existing research findings depend on the organisational form of a purchasing group. In addition, it is concluded that it is not possible to put all different organisational forms in one box. 
Still, several researchers dealing with cooperative purchasing do not clearly define and position the studied forms. This makes it difficult to compare the research findings of different researchers and to conduct reliable research. In an article by Long and Marquis (1999), an example is described of a lack of distinction between different forms of cooperative purchasing. Long and Marquis found that some of the studied effects fell short of their expectations. They thought that this may be because they did not make a distinction between different forms of cooperative purchasing. In their article, Long and Marquis claim that they found much stronger effects when they considered different forms separately in another study. Here, it is concluded that it is important to clearly define and position the studied organisational form of a purchasing group.

If the organisational forms of cooperative purchasing are not clearly defined and positioned, then it is difficult for academics and practitioners to identify which advantages, disadvantages, critical success factors, drivers, and preconditions apply to which form. In addition, in the early stages of a purchasing group, when the aim is to find a suitable form of cooperative purchasing, it is not clear how to design a group in which the different dimensions of the group fit together and fit the external circumstances.

A typology of organisational forms of cooperative purchasing can serve as a guideline for the aspects described above. A typology identifies multiple ideal organisational forms, each of which represents a unique combination of organisational dimensions that are believed to determine an optimal result (Doty and Glick, 1994). For instance, a typology shows that a very large purchasing group managed by a third party is the best form when many organisations have the same generic purchasing need and agree to outsource most of the purchasing steps to an external party. A small and intensive group is the best form when a small number of large organisations have a similar purchasing need for a specific product or service and all organisations need to be able to influence the specifications and supplier choice. A typology can also serve as a guideline when the aim is to solve managerial problems in a purchasing group. For example, the managers of an intensive purchasing group in which the total number of members is growing and the roles of the members turn out to differ a lot may decide to change the organisational form to a less intensive form of cooperative purchasing. Thus, a typology can be used to understand, design, and manage purchasing groups.

It is noted that existing relevant classifications and typologies mostly apply to vertical interorganisational relationships or strategic cooperation in general (e.g. Klein Woolthuis, 1999). These classifications and typologies have not been developed for the specific context of cooperative purchasing. Still, these models can be used for cooperative purchasing. However, this may not always be possible as there are some unique characteristics involved in cooperative purchasing. The following characteristics may distinguish cooperative purchasing from cooperating in other fields: the large possible number of group members, the large possible number of dissimilarities between group members, and the specific purchasing perspective. To obtain economies of scale in horizontal buyer-buyer relationships, purchasing groups may have a large number of group members. And as long as the group members purchase similar items, there may also be several dissimilarities between the members, such as differences in organisational structure, policy, market, life span, and size. Vertical relationships usually do not show such characteristics. In vertical relationships, the cooperation is usually intensive as new technologies or skills may be developed, processes may be improved or geared to one another, et cetera. Because of this, the number of members 
and the dissimilarities between the members are often low. Hence, vertical classifications and typologies are not fully applicable to all forms of horizontal buyerbuyer cooperation.

Some empirical research has already been done on different forms of cooperative purchasing (e.g. Arnold, 1996; Aylesworth, 2003; Bakker et al., 2007; Hendrick, 1997; Kamann et al., 2004; Kivisto et al., 2003; Nollet and Beaulieu, 2003). However, most of the relevant literature describes only one or two forms of cooperative purchasing without clearly positioning the forms. In addition, the existing literature mostly considers a limited number of main dimensions. This article builds on all these main dimensions, which are:

- Extent of the costs and gains for the members (based on Nollet and Beaulieu, 2003);

- Influence by all members on the activities of the group (Galaskiewicz, 1985);

- Number of different activities for the group (based on Dyer and Singh, 1998);

- Organisational design of the group (based on Enthoven, 1994);

- Member characteristics (based on Klein Woolthuis, 1999);

- Size of the group (Nollet and Beaulieu, 2003);

- Life span of the group (D'Aunno and Zuckerman, 1987; Johnson, 1999; Nollet and Beaulieu, 2003).

\section{Method}

\subsection{Data sources and data collection}

In order to get a more complete understanding of different forms of cooperative purchasing, an intensive literature review and twenty-one semi-structured interviews were carried out in 2003 and 2004 among purchasing managers of fifteen different purchasing groups in the public sector. These groups were chosen with an attempt to represent a variety of groups. The groups consisted of hospitals, municipalities, universities, government departments or police stations and varied in organisational structure, size, life span, et cetera. One purchasing group was studied in more detail than the others by also observing the meetings of the group for over three years. Additional interviews were carried out with the members of the group to discuss the group events into more detail. The literature and the empirical study have contributed to our understanding of the dimensions, activities, organisational structure, development, disadvantages, advantages, and the critical success factors of different forms of cooperative purchasing. The outcomes of this research phase were lists of properties of different purchasing groups.

Based on these outcomes, a practical book was written about cooperative purchasing. Three purchasing managers were involved in this book project by describing additional case examples about their purchasing groups. Two more purchasing managers were involved in the project by describing case examples about why they made an explicit choice not to join a purchasing group. These case descriptions further improved our understanding of different forms of cooperative purchasing. To validate, improve, and evaluate the progress and content of the project, there were two meetings with a focus group of four purchasing managers. These purchasing managers were actively involved in different purchasing groups consisting 
of municipalities or hospitals. The purchasing managers involved in the project were considered to be practical experts in cooperative purchasing.

\subsection{Procedure}

One of the main objectives of the project was to develop an initial typology of organisational forms of cooperative purchasing. This typology has been developed in the context of discovery (Reichenbach, 1938) and pursuit (Laudan, 1977). Because the project focused on finding typical organisational forms of cooperative purchasing, the research procedure was highly iterative. Data and theory were continuously compared until patterns clearly emerged and additional data and theory no longer added to the refinement of the typology (Eisenhardt, 1989; Kirk and Miller, 1986; Shenhar, 1998). The main steps of the research procedure were as follows.

Based on the main dimensions mentioned in Section 2, several subdimensions that play an important role within purchasing groups were identified. These subdimensions were identified based on our theoretical and empirical findings extended with subdimensions described in academic publications dealing explicitly with cooperative purchasing (see also Appendix 1). The selection of subdimensions was completed by including subdimensions from the literature on cooperation and management in general. Section 5 explicitly refers to the sources of the subdimensions.

The scores on the dimensions for the different forms were determined by theoretical specification. The theoretical specification required expert raters to develop the ideal scores for the different organisational forms of cooperative purchasing (Doty et al., 1993; Segev, 1989). During our interviews and focus group meetings, dimension properties and dimension scores were therefore discussed with practical and academic experts in cooperative purchasing. Simultaneously, the theoretical foundations of the scores were developed, which are discussed in Section 4. In the typology, only dimensions that have different scores for different forms were included. By doing so, several main forms of cooperative purchasing were determined.

The final phase of the research project consisted of a presentation of our findings at an annual conference for practitioners in the public sector. Our findings were distributed to 4000 members of a purchasing association and are available online with a request for feedback on the key issues and on any perceived discrepancies. From practitioners, academics, and students, several responses were received which were used to further refine the typology.

\section{Descriptions of organisational forms of cooperative purchasing}

In this section, five forms of cooperative purchasing are discussed. For each form, the main dimensions described in Section 2 and several subdimensions are described and discussed. The five forms are called piggy-backing groups (Section 4.1), third party groups (Section 4.2), lead buying groups (Section 4.3), project groups (Section 4.4), and programme groups (Section 4.5). For all these forms, road transport is used as an analogy. 


\subsection{Piggy-backing groups}

Piggy-backing groups are informal purchasing groups and focus on keeping the cooperation as simple as possible. In some cases, this form of cooperative purchasing only involves the sharing of purchasing information and knowledge with other organisations in a large network. But most of the times, it involves a relatively large organisation which establishes a contract on its own specifications. This contract may be used by some smaller organisations under (almost) the same contract conditions. This concept is known as piggy-backing. For the piggy-backing organisations, the concept can be quite beneficiary due to reduced transaction costs and reduced purchasing prices. However, for the hosting organisation, there is no direct incentive to allow others to piggy-back on its contracts. Sometimes, the host manages to negotiate a somewhat lower purchasing price due to the somewhat larger purchasing volume, but this is often the exception rather than the rule. Allowing others to piggy-back even involves some costs for the host, such as extra negotiation costs. Therefore, to make a piggy-backing group work on the long term, the host should preferably receive some compensation (Schotanus, 2005a).

An analogy for piggy-backing is hitchhiking. Piggy-backing organisations usually cannot influence the purchasing specifications and supplier choice, such as a hitchhiker on the road usually cannot influence the final destination of its ride. Therefore, the coordination costs of piggy-backing are low, but the concept is not always applicable. Another difficulty of piggy-backing is the availability of information. Often, organisations are not aware they have the possibility to piggy-back on contracts of others. In addition, in some countries, legislation makes it more difficult for public organisations to allow piggy-backing. This is the case when the purchasing volume with a current supplier would increase a lot due to piggy-backing, while this potential increase is not mentioned in the original public tender. If this is not mentioned, then the other prospective suppliers did not have full information at their disposal. This contravenes with aspects such as transparency and equal treatment. A final difficulty is that suppliers do not always allow smaller organisations to piggy-back on the contract of a large organisation under the same conditions. This aspect can be solved by a somewhat higher purchasing price with the other conditions unchanged. Despite this higher purchasing price, there still remain reduced tender process times and transaction cost savings, which are advantageous both to the buyers and the supplier (Arnold, 1996). Another advantage for the supplier is that it might be beneficial to supply a whole region of cooperating organisations in one sector.

A practical example which resembles a relatively intensive piggy-backing group is the group of the municipality of Groningen and several other local governments in three different provinces in the Netherlands. This purchasing group has been active for more than two decades ${ }^{1}$ and covers about twenty common products and services. Groningen is relatively large compared to the other organisations and allows the others to piggyback on its contracts. When purchasing managers of Groningen negotiate a new contract for their own organisation, they ask the supplier whether it is possible for the smaller governments to piggy-back on the contract. The smaller governments are free in their

\footnotetext{
${ }^{1}$ Some studies consider an alliance's longevity a benchmark for success (Hagedoorn, 1994; Hoffmann,
} 
choice to piggy-back and to make use of the scale and expertise of Groningen.

Groningen receives a small fee from the suppliers to cover the expenses related to the purchasing group, such as helpdesk costs.

\subsection{Third party groups}

Third party groups mostly involve long term piggy-backing made possible by public or private external parties or central authorities with devoted resources. A third party is a for-profit organisation or a non-profit organisation and may be owned by the members of the group. The third party may host forum websites for purchasing discussions and establish new contracts for common products and services on behalf of and for use through e-procurement or direct use by all the members. Thus, the third party focuses on achieving a large scale and it carries out most of the purchasing activities by itself. The purchasing activities are based on the (expected) aggregate purchasing volume and are carried out with the specific purchasing expertise of the external party (Harland et al., 2003). The members do not have to communicate with each other. So, just like in a piggy-backing group, the members do not have to form a high involvement relationship with each other, nor do they have to discuss the purchasing specifications (Aylesworth, 2003). The members only have to have a formal relationship with the hosting organisation or the third party.

An analogy for a third party group is a bus service. Most of the times, there is no limit to the total number of members of a third party group (i.e. the total number of bus travellers), but the members do have to pay a membership fee (i.e. a bus ticket) to cover the costs made by the third party. A disadvantage of third party groups is that the members usually have hardly any control over the purchasing process. Thus, the members cannot really influence the purchasing specifications and supplier choice. Because of this, custom-made items are usually not suitable for third party groups. Finally, it may be difficult for SMEs to supply to very large third party groups. This can be solved by dividing some of the purchasing needs into smaller parts. For further discussions on how electronic third party groups work, see Corsten and Zagler (1999) and Huber et al. (2004). For further discussions on how third party groups may develop over time, see D'Aunno and Zuckerman (1987), Johnson (1999), and Nollet and Beaulieu (2003).

Practical examples of third party-like groups are regional or national purchasing organisations or member-owned service bureaus (Aylesworth, 2003). Third party groups are especially popular in the health sector in the United States. This sector has a long history of cooperative purchasing. Currently, third party groups cover a large percentage of the products and services purchased by health care institutions in the United States.

\subsection{Lead buying groups}

A lead buying group involves outsourcing purchasing activities to one of the other members of the group: each item is purchased by the most suitable organisation or external party according to their expertise, resources or purchasing volume. This concept enables the members of a group to specialise in purchasing typical items. Some consideration and evaluation meetings will be necessary to determine which member should carry out which activities. These meetings also allow the members to influence 
to some extent the tenders put out by the others. It is difficult to apply the concept of lead buying to a one-time event. In a one-time lead buying group (i.e. a charter group), chances are high that the leading members are not fully compensated for their efforts. A possible solution is to hire an external party that carries out most of the activities. Still, a one-time lead buying group is not considered as a main form of cooperative purchasing.

An analogy of lead buying is carpooling. Sometimes, one organisation drives the group members to a certain destination. Another time, another organisation provides the car and the driver. The advantages and disadvantages of lead buying are similar to the advantages and disadvantages of outsourcing purchasing activities in general. For example, a disadvantage of a lead buying group is that the members become dependent on the knowledge and skills of the other members. This applies especially to groups in which the members differ in size and expertise. To become a successful intensive purchasing group, the members should have at least some similarities, such as the same geographical location, a similar network, et cetera. As more consultation is necessary with lead buying than with third party purchasing, lead buying groups usually have less members. A more intensive form of cooperative purchasing than lead buying is necessary when all the members have to work together on purchasing complex products or services. Section 4.5 mentions some similarities and differences between lead buying groups and more intensive purchasing groups.

An example of agreements used in relatively small purchasing groups are best price agreements: if one member receives a better price from a supplier for a shared item while renegotiating a contract, then all members also buying from this supplier should receive this reduced price from this supplier.

A practical example which resembles a large lead buying group is the purchasing group of the Dutch regional police forces. Most of the purchasing departments of the Dutch police force are represented in this purchasing group. In subgroups, some of the members lead purchase together on a small scale for tendering products and services such as cleaning services. On a larger scale, products like police cars are purchased cooperatively. Lower prices and reduced transaction costs have been achieved. However, it has been proven to be difficult to share purchasing activities with less advanced purchasing organisations.

\subsection{Project groups}

A project group is an intensive form of cooperative purchasing. Typically, a project group is a one-time purchasing group for a shared purchasing project. The members of the group bundle their forces for one time and together, they carry out the purchasing activities. Thus, the members focus on a shared problem and try to learn from each other during the project. In addition, the members share supply risks and knowledge. The members meet regularly during the project, but as the purchasing group is a onetime event, the organisational structure is quite simple. For instance, a steering committee is usually not necessary. Because a typical project group is a one-time event, the number of different cooperative activities for the group is limited. The group usually breaks up after the project ends, but if the project is successful and the members share more purchasing needs, then the project group could be continued as a lead buying group (see Section 4.3) or a programme group (see Section 4.5).

An analogy of a project group is a convoy on the road. Here, a convoy is defined as a unique combination of independent trucks. Together, the trucks bundle their forces 
and drive to the same destination for one time. In contrary to other intensive forms of cooperative purchasing, project groups usually do not ask for much bonding, which requires a long term process (Kamann et al., 2004). Project groups do involve a lot of consultation between the members to bring the specifications up to the same level, to agree with one another on the supplier choice, et cetera. It can be difficult to work together with members who do not know each other very well. Particularly in a project group, one should prevent potential free riding problems or at least try to limit its effects. If an organisation is still carrying out more work than the other organisations, then this organisation should preferably be compensated.

A practical example which resembles a project group combined with a piggybacking group is OT2000. OT2000 was a very large purchasing group for telephony services involving 311 public organisations. A small number of organisations in a steering committee were involved in the actual tendering process. The other organisations piggy-backed on the cooperative contract. Therefore, it was difficult to involve all the final users of the telephony services during the tendering processes. Another difficulty was that the organisations that were involved in the actual tendering process were mostly located near one municipality. Piggy-backing organisations in regions further away were not supplied as good as the organisations near the municipality. The allocation of gains and costs was also considered to be difficult. Despite the difficulties, substantial average savings on the purchasing price were gained and the overall service level was improved. The coordination costs were high though and mostly allocated to the organisations actively involved in the tendering process. Some organisations evaluated the purchasing group as quite successful. Others evaluated it as hardly successful or not successful at all.

\subsection{Programme groups}

Intensive cooperative purchasing forms, such as programme groups, often involve representatives of the management teams of the cooperating organisations meeting regularly in a steering committee to discuss cooperative projects. The members have high involvement relationships with each other and all can influence specifications, supplier selections, et cetera. Cooperative projects are usually carried out by at least one member of the steering committee together with representatives of all cooperating organisations. Together, they carry out several steps of the purchasing process. Thus, the members share the administrative work and focus on learning from each other and on reducing transaction costs.

Programme groups and lead buying groups often have a similar organisational structure. In addition, to be able to work effectively, several purchasing processes are usually standardised or synchronised in both group types. Still, there is one major difference. The activities for a cooperative project for a lead buying group are carried out by the personnel of one organisation and not by different organisations. In a lead buying group, there are therefore less learning opportunities. Because the cooperative processes are less complex in a lead buying group, there are also less transaction costs and the group can have more members.

Intensive forms of cooperation are structured informally or formally. Formal groups can be separate legal entities owned by their members. Formal groups can also be highly structured groups without legal entities. Criteria for formality are regular organised meetings and the use of several procedures and rules, such as joining and 
leaving rules, duties and rights, et cetera. Usually, the more trust, commitment, need, experience or knowledge on how to work together is available, the less formality is necessary (Klein Woolthuis, 1999). More formality is necessary with mandatory cooperation, higher financial or legal risks and interests, mutual competition, less organisational similarities or when one or more members have a formal culture.

An analogy of a programme group is an F1-team. Programme groups and F1-teams are intensive forms of cooperation and everyone involved plays an important role. Programme groups regularly make use of a private or public external party to coordinate some of the activities. A programme group can have one contract between the group and the supplier for a product or service, but typically, each member has an individual contract with the shared supplier. A typical difficulty for programme groups in the private sector is the sharing of confidential information. Typical difficulties for all programme groups are communication problems (Laing and Cotton, 1997) and the allocation of savings (Schotanus, 2005b). The allocation of savings can be difficult when the members differ in several aspects, such as organisational size or purchasing skills. In any case, allocation methods can be used to compensate unequal roles of members or inequality between members. In practice, the costs and workloads are often allocated equally or proportionally between the members. Note that in the literature, it is discussed that allocating the costs and workloads equally is usually fairer and more stable on the long run (Schotanus, 2005b).

Note that the more integration of the purchasing processes of the members takes place, the more the aspects mentioned in alliance theory apply (Kamann et al., 2004). This means that if the cooperation is very basic and non-intensive, then alliance theory aspects, such as transparency, trust, and commitment, are less important. Intensive forms of cooperative purchasing ask for more organisational similarities and mutual communication. Therefore, for intensive forms, the coordination costs are higher and the total number of members is lower than for non-intensive forms (Schotanus, 2005a).

Large organisations active in cooperative purchasing are usually involved with intensive forms of cooperating. The larger the organisation, the less profitable it will be to piggy-back on another's contract as more specific contracts are often necessary. Small organisations are usually involved with third party purchasing and piggy-backing (Quayle, 2002), as they lack economies of scale on their own (Schotanus, 2005a).

A practical example of a programme-like group is Netwerkstad Twente, a purchasing group of four municipalities. The municipalities share several contracts despite some organisational differences. The municipalities found several opportunities for cooperative purchasing by analysing and diagnosing their purchasing spend. Difficulties arise occasionally due to the organisational differences. For instance, the municipalities find it to be difficult to cooperatively improve the professional level of their purchasing functions. It is also difficult to allocate the costs and gains in a fair manner. This is because the costs and gains have a complex structure and are difficult to calculate. Still, all members evaluate the group as successful as most of the shared projects lead to lower purchasing prices and/or an improved quality of the purchased products and services.

Appendix 2 classifies the academic publications that deal directly or indirectly with the main forms of cooperative purchasing. Interested readers can find typical aspects and some more information about the main forms in these articles. 


\section{A typology of organisational forms of cooperative purchasing}

In Table 2, the ideal scores on several dimensions are provided for the different forms. Based on Section 4 and the studies mentioned in Appendix 2, the scores for the dimensions were determined on a range from low to high. Most of the scores are based on Section 4 as most of the academic publications in Appendix 2 only describe a limited number of scores.

Table 2

A typology of organisational forms of cooperative purchasing

\begin{tabular}{|c|c|c|c|c|c|}
\hline \multirow[t]{2}{*}{ Dimensions } & \multicolumn{5}{|c|}{ Group } \\
\hline & $\begin{array}{l}\text { Piggy- } \\
\text { backing }\end{array}$ & $\begin{array}{l}\text { Third } \\
\text { party }\end{array}$ & $\begin{array}{l}\text { Lead } \\
\text { buying }\end{array}$ & Project & Progr \\
\hline \multicolumn{6}{|c|}{ 1. Objectives (based on Nollet and Beaulieu, 2003) } \\
\hline Total gains for all members & low-med & med-high & med & low-med & \\
\hline Total costs for all members & low & med & med & med & \\
\hline \multicolumn{6}{|c|}{ 2. Influence by all members on the activities of the group (Galaskiewicz, 1985) } \\
\hline Complexity for all members & low & low & med & high & high \\
\hline Equal roles within the group & low & low & med & high & high \\
\hline Independency on the skills of others & low & low & med & high & high \\
\hline Intensiveness for all members & low & low & med & high & high \\
\hline \multicolumn{6}{|c|}{ 3. Number of different activities for the group (based on Dyer and Singh, 1998) } \\
\hline Diversity of activities for the group & low & high & med & low & high \\
\hline \multicolumn{6}{|l|}{ 4. Organisation (based on Enthoven, 1994) } \\
\hline Formalisation of the group & low & high & low-med & med-high & low-n \\
\hline Free riding prevention mechanisms ${ }^{\mathrm{a}}$ & low & low & low-med & med-high & low-1 \\
\hline Savings allocation mechanisms $\mathrm{s}^{\mathrm{a}}$ & med-high & high & low-med & low-high & low-m \\
\hline Group adaptation to specific needs & low & low-med & med & high & high \\
\hline Group resources & low-med & high & med & med & med \\
\hline Self-management ${ }^{\mathrm{b}}$ & low & low & med & high & high \\
\hline Standardisation of member policy, plans, etc. & low & low & med-high & low & med- \\
\hline
\end{tabular}

5. Member relationships (based on Klein Woolthuis, 1999)

Minimum level of commitment of members low low-med med-high high high Minimum level of coterminosity of members low-med low med-high med-high med-high Minimum level of homogeneity of demand high med-high med-high med med Minimum level of uniformity of members ${ }^{c}$ low low med med-high med-high Minimum level of trained member personnel low low med-high high high

6. Size (Nollet and Beaulieu, 2003)

Number of joint activities

Number of members

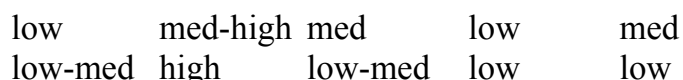

7. Life span of the group (D'Aunno and Zuckerman, 1987; Johnson, 1999; Nollet and Beaulieu, 2003) Expected life span of the group low-med high high low high

Note: The subdimensions are based on: gains and costs (Nollet and Beaulieu, 2003), complexity (Johnson, 1999), independency (Essig, 2000), intensiveness (Klein Woolthuis, 1999; Williams, 2005), devoted resources (Bakker et al., 2006; Nollet and Beaulieu, 2003), formalisation (Ball and Pye, 2000; Dyer and Singh, 1998; Johnson, 1999), free riding prevention (Dyer and Singh, 1998; Johnson, 1999), savings allocation mechanisms (Heijboer, 2003; Schotanus, 2005b), self-management and decentrality (Bakker et al., 2006; Williams, 2005), control (Schotanus, 2005a), joint decision making (Laing and Cotton, 1997), standardisation (Bakker et al., 2006), committed members (Williams, 2005), coterminosity (Exworthy and Peckham, 1998), homogeneity of demand (Bakker et al, 2007; Rozemeijer, 2000), and number of members (Bakker et al., 2007; Nollet and Beaulieu, 2003).

a Characteristics of subdimensions that differ from the subdimension above

b Can also be defined as joint meetings, control, decisions by all members, and/or decentrality 
c For instance, uniformity of organisational structure, size, policy, market, and life span

Based on Table 2, it is noticed that within the forms of cooperative purchasing several differences may exist. For example, programme groups can be more or less informally or formally structured. In addition, it is noted that not all dimensions are formulated at the same level, because some dimensions are more abstract than others.

Based on Doty and Glick (1994), it is noted that the typology can be tested on a large scale in further research. This can be done by examining the extent to which deviation from the ideal scores on the dimensions predicts failure or a relatively low performance of a purchasing group (Doty and Glick, 1994). In addition, Venkatraman (1989) argues that a high degree of adherence to an ideal profile should be positively related to performance. Venkatraman refers to this degree of adherence to an ideal profile as profile deviation.

Profile deviation requires developing weights for the dimensions based on their relative theoretical importance to the context. In some situations, it is assumed that each dimension is equally important (Segev, 1989; Venkatraman, 1989). In other situations, the weights are assumed to be unequal (Mintzberg, 1979, 1983). Table 2 has already distinguished main dimensions from subdivisions, but a more explicit distinction could be made in further research. De Boer (1998) refers to several ways of deriving weights including analytical hierarchy process (Saaty, 1980). Alternatively, Venkatraman (1989) suggests using preference-mapping techniques (Carroll, 1973) or regression equations (Venkatraman and Prescott, 1990).

The final step in testing the typology is comparing the weighted theoretical dimension scores with the weighted dimension scores of well performing and underperforming purchasing groups. To this end, Doty and Glick (1994) suggest several techniques for assessing profile deviation including coefficients of pattern similarity (Cattell, 1949), D-statistic (Cronbach and Gleser, 1953), and q-techniques (Miller, 1978).

\section{Positions of organisational forms of cooperative purchasing}

In Section 5, it was noticed that there are several differences within each of the forms of cooperative purchasing. Still, there are also dimensions which distinguish the forms from each other. Section 6.1 discusses the theory behind two distinguishing dimensions. Section 6.2 positions the forms in a matrix according to these dimensions.

\subsection{Distinguishing dimensions for organisational forms of cooperative purchasing}

Cooperative purchasing can be explained by several theories as new institutional economics, transaction cost economics, resource-based view, network theory, and organisational learning theory (Arnold, 1996; Kamann et al., 2004; Tella and Virolainen, 2005). Based on new institutional economics and transaction cost economics (Williamson, 2000), a wide range can exist of different hybrid organisational forms of cooperative purchasing. These organisational forms are defined as coordination by network and range between coordination by hierarchy and coordination by market (Arnold, 1996; Galaskiewicz, 1985; Jones and Hill, 1988; Thompson et al., 1991). That is why purchasing groups are organised in quite a number of different ways. 
In some cases, an organisational form leaning to coordination by hierarchy is a suitable form. This is the case when several organisations work together in a large exceptional purchasing project and all need to agree on the specifications and supplier choice. In other cases, an organisational form leaning to coordination by market is more suitable. This is the case when several organisations have the same purchasing need for a common commodity and agree to outsource most purchasing steps to an external party. In all cases, the members continue to exist as separate organisations, but they do combine their purchasing power.

The dimension 'coordination from hierarchy to market' relates to the intensiveness for the members of a purchasing group. Intensiveness is defined as the extent to which a group member is compelled to perform an active role in a purchasing group. In a third party group, the members are not very active as the work is usually done by the third party. In a programme group, the group members perform an active role. As a result of this active role, the members of a programme group can influence most of the purchasing activities of the group. The higher the intensiveness for the members in a purchasing group is, the more the organisational form leans to coordination by hierarchy. The lower the intensiveness is, the more the organisational form leans to coordination by market. Indicators for this intensiveness dimension are described in Table 2. All the dimensions related to this intensiveness dimension are quite specific to the forms of cooperative purchasing, i.e. they should not differ heavily within one or more of the forms. For this reason, this dimension is chosen as one of the axes.

Another dimension in Table 2, which should not differ heavily within one or more of the forms, is related to the actual activities of a purchasing group. This dimension is defined as the 'number of different activities for the purchasing group'. It ranges from undertaking 'one occasional cooperative activity' to 'continuously undertaking different activities'. These activities are carried out by an external party or by the members themselves. Because this dimension is also specific to the forms of cooperative purchasing, this dimension is chosen as the second axis.

\subsection{A matrix for organisational forms of cooperative purchasing}

To be able to position the different forms of cooperative purchasing, a matrix was developed as illustrated in Fig. 1. A fitting matrix was found for all the forms by using the two dimensions which were discussed in Section 6.1.

\begin{tabular}{|c|c|c|c|}
\hline \multirow{5}{*}{ 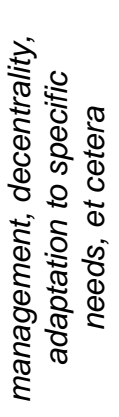 } & \multirow{5}{*}{$\uparrow$} & Project group & Programme group \\
\hline & & Analogy: Convoy & Analogy: F1-team \\
\hline & & $\begin{array}{l}\text { Keywords: Focus on learning and reducing } \\
\text { transaction costs; one-time event }\end{array}$ & $\begin{array}{l}\text { Keywords: Focus on learning, reducing } \\
\text { transaction costs, and standardisation }\end{array}$ \\
\hline & & $\begin{array}{l}\text { Dimensions: Typically, short term; few } \\
\text { contracts; few to medium number of meetings; } \\
\text { few members; formal; specific need }\end{array}$ & $\begin{array}{l}\text { Dimensions: Typically, long term; medium } \\
\text { number of contracts; many meetings; } \\
\text { few members; informal; from specific to }\end{array}$ \\
\hline & & $\begin{array}{l}\text { Problems: Typically, free riding; } \\
\text { communication; purchasing processes may } \\
\text { slow down a lot }\end{array}$ & $\begin{array}{r}\text { generic needs } \\
\text { Problems: Typically, member differences may } \\
\text { cause problems; communication }\end{array}$ \\
\hline
\end{tabular}


It is difficult to apply the concept of lead buying to a one-time event (see Section 4.3)
Lead buying group

Analogy: Carpooling

Keywords, dimensions, and problems:

Similar to a programme group, but differences are: activities for a project are carried out by one party; skill specialisation; more members; less learning opportunities; members depend on each other's skills and efforts

\section{Third party group}

Analogy: Bus service

Keywords: Focus on scale; third party with specific resources; fair allocation of savings; there is a membership fee

Dimensions: Typically, long term; medium to many contracts; few meetings for many members; formal; relatively generic needs

Problems: Typically, members can hardly influence activities; SME suppliers may object concept is not always applicable

low number of different group activities

activities: specifying, selecting, contracting, evaluating, sharing information or knowledge, sharing personnel or other resources, shared policy and procedures, benchmarking, et cetera Fig. 1. A matrix for organisational forms of cooperative purchasing: The highway matrix

It follows from Fig. 1 that a programme group can be used when members want to learn from each other. In addition, a programme group can be used for specific to generic purchasing needs. A similar argumentation can be applied to the other dimensions (see also Table 2) and to the other forms of cooperative purchasing.

For specific situations, hybrid forms of cooperative purchasing should be set in place. For instance, a hybrid form often occurs between a lead buying group and a programme group. In this hybrid form, the activities for a cooperative project are carried out by a limited number of members. This hybrid form can have more members than a programme group. Hybrid forms can also occur between a third party group and a lead buying or programme group (i.e. a private bus service group). Private bus service groups can have more members than a project or programme group. In addition, these hybrid forms usually involve an external party or a steering party. This party carries out some of the work for the group.

Combinations between forms are also possible. For instance, project, lead buying, and programme groups often allow piggy-backing. Here, it is noted that the combined purchasing group OT2000 (see Section 4.4) was not a success for several of its members. One of the possible reasons for this was that the hosting organisations were not compensated for their efforts. Another frequently occurring combination is the combination between a programme group and a lead buying group. In this combined form, the activities for a cooperative project are sometimes carried out by an external party or one member (i.e. lead buying). For other cooperative projects, the activities are carried out by all the members (i.e. programme purchasing). For the management of the members, it is important to cooperatively agree on when to use which form. Usually, low-interest items, which are not custom-made, are suitable for lead buying. These 
items are suitable as the other members do not care much about the specifications and supplier choice. Usually, medium-interest items are more suitable for programme groups.

In further research, a refinement of the matrix may be possible by discussing more detailed descriptions of hybrid forms. A further refinement of the matrix may be possible by slightly adapting the two distinguishing dimensions or by introducing more dimensions.

\section{Conclusion}

The first objective in this paper was to describe the main ideal forms of cooperative purchasing. Five ideal forms were identified and described. These forms range from a relatively simple form as a piggy-backing group to a relatively complex form as a programme group.

The second objective was to develop a typology of different forms of cooperative purchasing to better understand, design, and manage purchasing groups. Based on existing research, our own findings, organisational structure theory, and new institutional economics, several dimensions of different forms of cooperative purchasing were described. The main identified dimensions are: (1) extent of the costs and gains for the members, (2) influence by all members on the activities of the group, (3) number of different activities for the group, (4) organisational structure of the group, (5) member characteristics, (6) size of the group, and (7) life span of the group (see Table 2 for the complete typology).

The third and final objective was to position the different forms of cooperative purchasing. To be able to position the forms, a matrix was developed according to two distinguishing dimensions (see Fig. 1). The distinguishing dimensions are dimensions (2) and (3). The other five dimensions provide more information about the forms, but do not distinguish all forms from each other.

Clearly defining and positioning studied forms of cooperative purchasing is important as different forms imply different research models and mechanisms. Critical success factors, advantages, and disadvantages may differ per form as well. This implies that some of the forms of cooperative purchasing are more suitable to certain situations than others. This paper adds to existing literature by providing more insight into several dimensions of different forms, which is crucial to better understand why different forms fit different situations. Nevertheless, more research to the evolution of some forms of cooperative purchasing in more detail would be useful. More specifically, this applies to the right-hand side forms of Fig. 1. These forms are intensive or active and typically have a high expected life span.

The typology can serve as a guideline for (potential) purchasing groups when a suitable form needs to be chosen. In a suitable form, the different dimensions of a purchasing group fit together and fit the circumstances. For all purchasing groups, it is recommended to find the best balance between the different dimensions and the circumstances. Finding this balance is something in which the typology may help. As long as this balance is present, purchasing groups can maximise cooperative advantages and minimise related disadvantages. 


\section{Acknowledgements}

The authors thank Marieke van der Lans from the University of Twente, Elmer Bakker from the University of Bath, Mark van de Vijver and Esther Kersten from Tilburg University, Luitzen de Boer from the Norwegian University of Science and Technology, and the co-authors of the book "Inkoopsamenwerking, van theorie naar praktijk" (in Dutch) for their valuable contributions to the paper. The authors acknowledge partial financial support from the Dutch Association for Purchasing Management (NEVI). Finally, the authors thank the editor and the two anonymous reviewers for their constructive and valuable comments.

\section{Appendix A}

Academic publications dealing explicitly with cooperative purchasing.

\begin{tabular}{ll}
\hline Title (authors) & Main contribution to the field of cooperative purchasing \\
\hline Communication journals (1) & The authors describe the operations of different forms of cooperative purchasing. \\
Library purchasing & Their survey findings include: \\
consortia: The UK & - Most purchasing groups in their early stages are organised informally; \\
periodicals supply & - Suppliers to groups cite among other things volume of trade as an advantage; \\
market (Ball and Pye, & - Besides hidden savings, purchasing prices will always remain an issue for public \\
$2000)$ & money spending organisations.
\end{tabular}

Economics journals (1) ${ }^{\mathrm{b}}$

Multinational

corporations and

multinational buying

groups: Their impact on

Based on export data, the author argues that large retail buying groups in the United States, Europe, and Japan were the most important motor of manufactured export growth in Asia. In the future, the focus of buying groups on very low purchasing the growth of Asia's exports of manufacturesmyths and realities (Hone, 1974)

\section{General and strategy journals (2)}

A life-cycle model of organisational federations: The case of hospitals (D'Aunno and Zuckerman, 1987)

Influences on member commitment to group purchasing organisations (Doucette, 1997)
Based on literature, the authors propose a large purchasing federation development model in steps of: (1) coalition emergence, (2) transition to a federation, (3)

federation maturity, and (4) critical cross roads. The authors develop 15 hypotheses that mainly focus on the coalition emergence step.

The author notes the importance of large purchasing groups in some sectors in the United States, such as health care. In a survey, significant positive associations are found between member commitment and information exchange, trust, and the perceived commitment of other members. The suitability of alternatives to a purchasing group showed a significant negative relationship with commitment. It is argued that when a group member believes that the others are committed, the member will commit itself. To this end, some strategies are suggested.

Information systems and knowledge management journals (2)

Purchasing consortia and The authors used two surveys to assess the advantages of Electronic Purchasing electronic markets: A procurement direction in integrated supply chain management (Huber et al., 2004) Groups (EPG). They tested nine hypotheses and developed an EPG-adoption model. They show among other things that:

- Pressures from the business context do not have a significant impact on EPG importance to the purchasing strategy of organisations;

- EPG are positively correlated with the arm's length buyer-supplier relationship; 
- Purchasing size and purchasing maturity of organisations are important drivers to participate in EPG.

Credit based group The authors note that group negotiations are becoming essential in electronic negotiation for aggregate business and that the Internet makes it easier for consumers to join such sell/buy in e-markets (Yuan and Lin, 2003) negotiations. The authors present a group formation approach that is called credit based group negotiation. This approach facilitates the grouping of buyers and sellers and reaches favourable prices for both buyers and sellers.

\section{Management science, production, and operations journals (3)}

Formation of alliances in The authors note that competitors are more and more combining buying power in internet-based supply exchanges (Granot and Sošic, 2005) small e-marketplaces. An organisation that joins an e-group shares its suppliers with others, which may lead to more supplier competition. Questions raised are, when would an organisation prefer to take part in a group, when would it prefer that others join, and what are the consequences of joining? Experimental findings show among other things:

- If competing organisations have non-substitutable products, then the highest profit for each organisation is realised in a group with all competing organisations;

- The decrease in wholesale prices and processing costs realised by groups has a relatively minor effect on members' profits;

- If all group members benefit equally, the group could be stable.

The pattern of evolution in public sector purchasing consortia (Johnson, 1999)
Motives behind purchasing consortia (Tella and Virolainen, 2005)
The author develops a five stage conceptual model based on four cases of cooperative purchasing in steps of: (1) internal, (2) informal external, (3) developing external, (4), formal external, and (5) redevelopment. The author notes that purchasing groups show a lot of changes over time. They may become larger and become active in other fields than purchasing. In addition, several advantages (price reduction, reduced transaction costs, ability to attract new suppliers, support specialisation of staff, greater resources, and stronger management capabilities) and disadvantages (complexity, coordination costs, uncertainty, standardisation and compliance, free riding, governance, and declining cost savings) of purchasing groups are described. Finally, the increasing popularity of purchasing groups in the public sector is discussed.

The objective of the authors is to find the motives behind small purchasing groups. They review theoretical approaches explaining the cooperative purchasing rationale. The results of interviews indicate that the main motives of purchasing groups are cost savings and the collection of information on supply markets. Cost savings are mainly due to reduced transactions and increased negotiation power, what leads to lower purchasing prices.

Public sector journals (3) ${ }^{\mathrm{d}}$

On the ideal market structure for third-party purchasing of health care (Enthoven, 1994)

Public health insurance: the collective purchase of individual care (Evans, 1987)

The contribution of coterminosity to joint purchasing in health and social care (Exworthy and Peckham, 1998)
According to the author, the market structure for large scale third party purchasing in the health care must be managed by cooperative purchasing agents. These agents should structure and manage the enrolment process, create price-elastic demand, manage risk selection, and create and administer equitable rules of coverage. In the paper, undesirable political arrangements to be avoided are discussed as well.

The author notes that public health insurance is a mechanism for the cooperative purchasing of care on a large scale. The paper contrasts public coverage with private coverage. It is shown by comparative case studies how universal public coverage, used as a cooperative purchasing agency, has led to both better coverage and lower costs than private coverage.

The authors study the contribution of coterminosity (the coincidence of geographical boundaries between organisations) to cooperative purchasing. It is concluded that coterminosity has a contribution to purchasing organisations, but increasingly at a local level, such as the general practice. The manifestation of coterminosity may minimise the effects of fragmentation and encourage cooperation sensitive to local needs. Coterminosity is not considered as a 
precondition to cooperative purchasing, but is does carry some contributions.

\section{Purchasing and supply journals (4)}

Purchasing consortia as The author discusses that symbiosis is a precondition for cooperative purchasing. In symbiotic relationships: addition, the cooperative purchasing terminology is described. Finally, the concept developing the concept is compared to other sourcing types such as single and multiple sourcing.

of consortium sourcing (Essig, 2000)

Patterns of interorganisational purchasing : Evolution of consortia-based purchasing amongst GP fundholders (Laing and Cotton, 1997)
The development of group purchasing: an empirical study in the healthcare sector (Nollet and Beaulieu, 2003)
The author describes that general practice (GP) fundholders responded to the complexities of contracting by group purchasing. Based on interviews, three key issues of importance to the success of purchasing groups are found:

- Common objectives and interests should exist;

- Despite its recognised importance, communication was almost uniformly viewed as problematic. In part, these problems are attributed to political rivalry and the long established autonomy of practices. It is also argued that groups, being de facto compromise between centralised and decentralised purchasing, face as a consequence the worst aspects of communication problems inherent in both approaches;

- There was an inevitable tendency for decision making towards compromises. This stifled innovation in terms of contracting.

The authors develop a conceptual phase model for large purchasing groups in steps of: (1) birth, (2) growth, (3) maturity, and (4) concentration. Based on interviews, the authors identify several factors that may change over time: payers' intervention (e.g. legislation influences), nature of benefits, procurement strategy (e.g. diversification), nature of the relationship with suppliers (e.g. partnership), structure (e.g. confederal; autonomous) and resources (e.g. electronic catalogue).

Should an organisation The authors provide a framework to deal with the size of a purchasing group, its join a purchasing group? benefits, and its beneficiaries. Based on interviews, it was found that purchasing (Nollet and Beaulieu, 2005) groups are becoming increasingly popular. Despite its benefits (price reduction or lower price increases, reduction of administration costs, easy access to knowledgeable personnel, and sharing information), a purchasing group also constitutes an additional link in the supply chain with related drawbacks (price focus, potential supplier mergers, reduced supplier services, costs to maintain group cohesion, confidentiality of strategic information, determination of common objectives among members, and unclear beneficiaries might increase tensions).

Sociology journals (2) Third party buying: The trend and the consequences (Stinchcombe, 1984)

Interorganisational relations (Galaskiewicz, 1985)

The author notes that the trend towards large scale buying of health insurance, life insurance, and pension, and/or annuity plans through employers brings up problems of consumer sovereignty, problems of the incentives of service providers, and problems of availability of services which are only available through cooperative purchasing through employers. The paper analyses the incentive systems for stakeholders.

In cooperative purchasing, analysts have focused on power dependency and overcoming environmental uncertainty. The author notes that organisations have found a wide variety of ways to solve cooperative purchasing issues, ranging from coordination by market to hierarchy.

a The topics are based on the journal list of Harzing (2005), purchasing and supply has been added

b Publications and notes from law journals have been left out of the selection; interested readers can go back as far as 1924 for notes dealing with cooperative buying in Harvard Law Review

c The publications from Chen et al. (2002), Kauffman and Wang (2001), and Li et al. (2004), which deal with bid strategies in group buying auctions, have been left out of the selection

d These journals are all health management related journals 


\section{Appendix B}

Academic publications dealing with forms of cooperative purchasing.

\begin{tabular}{lll}
\hline Group & Academic publications & \\
\hline Piggy-backing & Exworthy and Peckham (1998) & \\
Third party & Ball and Pye (2000) & Huber et al. (2004) \\
& D'Aunno and Zuckerman (1987) & Johnson (1999) \\
& Doucette (1997) & Nollet and Beaulieu (2003) \\
& Enthoven (1994) & Nollet and Beaulieu (2005) \\
& Evans (1987) & Stinchcombe (1984) \\
& Exworthy and Peckham (1998) & Yuan and Lin (2003) \\
Lead buying & Ball and Pye (2000) & Johnson (1999) \\
& D'Aunno and Zuckerman (1987) & Laing and Cotton (1997) \\
& Exworthy and Peckham (1998) & Tella and Virolainen (2005) \\
& Granot and Sošic (2005) & \\
& & \\
Project & Exworthy and Peckham (1998) & Granot and Sošic (2005) \\
Programme & Ball and Pye (2000) & Granot and Sošic (2005) \\
& D'Aunno and Zuckerman (1987) & Laing and Cotton (1997) \\
& Exworthy and Peckham (1998) & \\
\hline
\end{tabular}

\section{References}

Ariño, A., de la Torre, J., 1998. Learning from failure: Towards an evolutionary model of collaborative ventures. Organization Science 9, 306-325.

Arnold, U., 1996. Cooperation of small and medium-sized companies in the field of purchasing framework and empirical data. NAPM conference proceedings, Portland (United States), 87-101.

Aylesworth, M.M., 2003. Purchasing consortia in the public sector, models and methods for success. ISM conference proceedings, Nashville (United States).

Bakker, E., Walker, H., Harland, C., Warrington, J., 2006. The effect of collaborative purchasing structures on managing cooperation. IPSERA conference proceedings, San Diego (United States).

Bakker, E., Walker, H., Harland, C., 2007. Organizing for collaborative procurement: An initial conceptual framework. IPP conference proceedings, Rome (Italy).

Bakker, E., Walker, H., Harland, C., 2006. Organising for collaborative procurement: An initial conceptual framework. In: Thai, K., Piga, G. (Eds.). Advancing public procurement: Practices, innovation and knowledge-sharing. Boca Raton, FL: PrAcademics Press, 14-44.

Ball, D., Pye, J., 2000. Library purchasing consortia: The UK periodicals supply market. Learned Publishing 13 (1), 25-35.

Barkema, H.G., Shenkar, O., Vermeulen, F., Bell, J.H.J., 1997. Working abroad, working with others: How firms learn to operate international joint ventures. Academy of Management Journal 17, 426442.

Boer, L. de, 1998. Operations research in support of purchasing. Design of a toolbox for supplier selection. Ph.D. dissertation, Enschede: University of Twente.

Carroll, J.D., 1973. Models and algorithms for multidimensional scaling, conjoint measurement and related techniques. In: Green, P.E., Wind, Y. (Eds.). Multiattribute decisions in marketing. Hinsdale, IL: Dryden Press, 335-37; 341-48.

Cattell, R.B., 1949. rp and other coefficients of pattern similarity. Psychometrika 14 (4), 279-298.

Chen, J., Chen, X., Song, X., 2002. Bidder's strategy under group-buying auction on the Internet. IEEE Transactions on Systems, Man, and Cybernetics Part A:Systems and Humans 32 (6), 680-690.

Chung, S., Singh, H., Lee, K., 2000. Complementarity, status similarity and social capital as drivers of alliance formation. Strategic Management Journal 21, 1-22.

Corsten, D., Zagler, M., 1999. Purchasing consortia and internet technology. IPSERA conference proceedings, Belfast and Dublin, 975-986. 
Cronbach L.J., Gleser G.C., 1953. Assessing similarity between profiles. Psychological Bulletin, 50, 456473.

Cruijssen F., Cools, M., Dullaert, W., Fleuren, H., 2006. Horizontal cooperation in logistics: Opportunities and impediments. Transportation Research E: Logistics, In press.

D'Aunno T.A., Zuckerman H.S., 1987. A life-cycle model of organizational federations: the case of hospitals. Acadamy of Management Review 12 (3), 534-545.

Doty, D.H., Glick W.H., Huber G.P., 1993. Fit, equifinality, and organizational effectiveness: A test of two configurational theories. Academy of Management Journal 36 (6), 1196-1250.

Doty, D.H., Glick, W.H., 1994. Typologies as a unique form of theory building: toward improved understanding and modeling. Academy of Management Review 19 (2), 230-251.

Doucette, W.R., 1997. Influences on member commitment to group purchasing organisations. Journal of Business research 40 (3), 183-189.

Dyer, J.H., Singh, H., 1998. The relational view: cooperative strategy and sources of interorganizational competitive advantage. Academy of Management Review 23 (4), 660-679.

Eisenhardt, K.M., 1989. Building theories from case study research. Academy of Management Review 14, 532-550.

Ellram, L.M., 1991. A managerial guideline for the development and implementation of purchasing partnerships. International Journal of Purchasing and Materials Management 27 (3), 2-8.

Enthoven, A.C., 1994. On the ideal market structure for third-party purchasing of health care. Social Science and Medicine 39 (10), 1413-1424.

Essig, M., 2000. Purchasing consortia as symbiotic relationships. European Journal of Purchasing and Supply Management 6 (1), 13-22.

Evans, R.G., 1987. Public health insurance: The collective purchase of individual care. Health Policy 7 (2), 115-134.

Exworthy, M., Peckham, S., 1998. The contribution of coterminosity to joint purchasing in health and social care. Health and Place 4 (3), 233-243.

Galaskiewicz, J., 1985. Interorganizational relations. Annual Review of Sociology 11, 281-304.

Granot, D., Sosić, G., 2005. Formation of alliances in internet-based supply exchanges. Management Science 51 (1), 92-105.

Hagedoorn, J., Schakenraad, J., 1994. The effect of strategic technology alliances on company performance. Strategic Management Journal 15 (4), 291-309.

Harland, C.M., Walker, H.L., Gronden, J. van de, Bloch, K., Ramm, N., 2003. UN case for the Budapest workshop, Procurement in the United Nations System. IRSPP conference proceedings, Budapest (Hungary).

Harzing, A.W., 2005. Journal Quality List. (14 ${ }^{\text {th }}$ ed.). University of Melbourne, [available at http://www.harzing.com].

Heijboer, G., 2003. Mathematical and statistical analysis of initial purchasing decisions. Ph.D. dissertation, Enschede: University of Twente.

Hendrick, T.E., 1997. Purchasing consortiums: Horizontal alliances among firms buying common goods and services: What? Who? Why? How? Tempe: Center for Advanced Purchasing Studies.

Hoffmann, W., Schlosser, R., 2001. Success factors of strategic alliances in small and medium-sized enterprises, an empirical study. Longe range planning 34 (3), 357-381.

Hone, A. 1974. Multinational corporations and multinational buying groups: Their impact on the growth of Asia's exports of manufactures-myths and realities. World Development 2 (2), 145-149.

Huber, B., Sweeney, E., Smyth, A., 2004. Purchasing consortia and electronic markets: A procurement direction in integrated supply chain management. Electronic Markets 14 (4), 284-294.

Ireland, R.D., Hitt, M.A., Vaidyanath, D., 2002. Alliance management as a source of competitive advantage. Journal of Management 28 (3), 413-446.

Johnson, P.F., 1999. The pattern of evolution in public sector purchasing consortia. International Journal of Logistics: Research and Applications 2 (1), 57-73.

Jones, G.R., Hill, C.W.L., 1988. Transaction cost analysis of strategy-structure choice. Strategic Management Journal 9 (2), 159-172.

Kamann, D.J., Vaart, T. van der, Vries, J. de, 2004. Joint purchasing: Theory and practice. IPSERA conference proceedings, Catania (Italy), 511-520.

Kauffman, R.J., Wang, B., 2001. New buyers' arrival under dynamic pricing market microstructure: The case of group-buying discounts on the internet. Journal of Management Information Systems 18 (2), $157-188$. 
Kenney, J.S., 2000. Examining and embracing the value of coalition participation. Employee Benefits Journal Brookfield 25 (1), 12-13.

Kirk, J., Miller, M.L., 1986. Reliability and validity in qualitative research. Sage University Series on Qualitative Research Methods 1, Beverly Hills, CA: Sage.

Kivisto, T., Virolainen, V.M., Tella, E., 2003. Consortia purchasing and logistics in Kuopio area - lessons learned from a 4-year project. IRSPP conference proceedings, Budapest (Hungary).

Klein Woolthuis, R., 1999. Sleeping with the enemy: trust, dependence and contract in interorganisational relationships. Ph.D. dissertation, Enschede: University of Twente.

Laing, A., Cotton, S., 1997. Patterns of inter-organizational purchasing : Evolution of consortia-based purchasing amongst GP fundholders. European Journal of Purchasing and Supply Management 3 (2), 83-91.

Laudan, L., 1977. Progress and its problems: Towards a theory of scientific growth. Berkeley: University of California Press.

Lambe, C.J., Spekman, R.E., Hunt, S.D., 2002. Alliance competence, resources, and alliance success: Conceptualization, measurement, and initial test. Journal of the Academy of Marketing Science 30 (2), 141-58.

Li, C., Chawla, S., Rajan, U., Sycara, K., 2004. Mechanism design for coalition formation and cost sharing in group-buying markets. Electronic Commerce Research and Applications 3 (4), 341-354.

Long, S.H., Marquis, M.S., 1999. Pooled purchasing, who are the players? Health Affairs 18 (4), 105111.

Miller D., 1978. The role of multivariate "q-techniques" in the study of organizations. Academy of Management review 3 (3), 515-531.

Mintzberg, H.T., 1979. The structuring of organizations. Englewood Cliffs, NJ: Prentice-Hall.

Mintzberg, H.T., 1983. Structure in fives: Designing effective organizations. Englewood Cliffs, NJ: Prentice-Hall.

Mitchell, W., Singh, K., 1996. Survival of businesses using collaborative relationships to commercialize complex goods. Strategic Management Journal 17 (3), 169-195.

Nollet, J., Beaulieu, M., 2003. The development of group purchasing: an empirical study in the healthcare sector. Journal of Purchasing and Supply Management 9 (1), 3-10.

Nollet, J., Beaulieu, M., 2005. Should an organisation join a purchasing group? Supply Chain Management 10 (1), 11-17.

Patterson, J.L., Forker, L.B., Hanna, J.B., 1999. Supply chain consortia: the rise of transcendental buyersupplier relationships. European Journal of Purchasing and Supply Management 5 (2), 85-93.

Quayle, M., 2002. Purchasing in small firms. European Journal of Purchasing and Supply Management 8, 151-159.

Reichenbach, H., 1938. Experience and Prediction. An analysis of the foundations and the structure of knowledge. Chicago: The University of Chicago Press.

Rozemeijer, F., 2000. Creating Corporate Advantage in Purchasing. Ph.D. dissertation, Eindhoven: Technical University of Eindhoven.

Saaty, T.L., 1980. The analytic hierarchy process. New York: McGraw-Hill.

Schotanus, F., Telgen J., Lans M., van der, 2004. Inkoopsamenwerking, van theorie naar praktijk (in Dutch). NEVI / PIA / University of Twente.

Schotanus, F., 2005a. Cooperative purchasing within the United Nations. IPSERA conference proceedings, Archamps (France), 961-973.

Schotanus, F., 2005b. Unfair allocation of gains under equal price in cooperative purchasing. IPSERA conference proceedings, Archamps (France), 975-986.

Segev, E. 1989. A systematic comparative analysis and synthesis of two business-level strategic typologies. Strategic Management Journal 10, 487-505.

Shenhar, A.J., 1998. From theory to practice: toward a typology of project-management styles. IEEE transactions on engineering management 45 (1), 33-48.

Stinchcombe, A.L., 1984. Third party buying: the trend and the consequences. Social Forces 62 (4), 861884.

Tella, E., Virolainen, V.M., 2005. Motives behind purchasing consortia. International Journal of Production Economics 93-94, 161-168.

Thompson, G., Frances, J., Levacic, R., Mitchell, J., 1991. Markets, hierarchies and networks. London: Sage.

Venkatraman, N., 1989. The concept of fit in strategy research: Toward verbal and statistical correspondence. Acadamy of Management Review 14 (3), 423-444. 
Venkatraman, N., Prescott, J.E., 1990. Environment-strategy coalignment: An empirical test of its performance implications. Strategic management journal 11 (1), 1-23.

Williams, T., 2005. Cooperation by design: structure and cooperation in interorganizational networks. Journal of Business Research 58 (2), 223-231.

Williamson, O.E., 2000. The new institutional economics: Taking stock, looking ahead. Journal of Economic Literature 38 (3), 595-613.

Wooten, B., 2003. Cooperative purchasing in the 21st century. Inside Supply Management 14 (2), 4-7.

Yuan, S.T., Lin, Y.H., 2004. Credit based group negotiation for aggregate sell/buy in e-markets. Electronic Commerce Research and Applications 3 (1), 74-94. 